\title{
Mediation Ethics in Europe
}

\author{
Michel Kallipetis*
}

As all professionals know, and lawyers in particular appreciate, questions of ethics in the conduct of one's practice are seldom clear cut. Everyone will agree that the basic principles themselves are fairly straightforward and can be expressed in simple terms. However the problem always arises when particular issues, usually unexpected, crop up which require the application of general principles to circumstances which are not 'black and white'.

So it is with mediation. The ethical principles by which mediators are expected to act are not controversial, but their application to situations which arise in mediation is not always the subject of agreement between mediators. Curiously, or perhaps inevitably, the more experienced mediators sometimes have greater difficulty giving a straight 'yes or no' answer to any particular problem which may arise. This has been borne out in many conferences and seminars where particular problems have been posed to a group of mediators and there has rarely been unanimity on the approach to be adopted in terms of ethical conduct.

There are, of course, two issues to be considered: the ethical conduct of the mediator and the ethical conduct of the lawyers representing clients in mediation. Each issue merits its own chapter, if not a complete volume, but as far as this contribution is concerned I shall deal solely with the first issue - the ethical standards expected of mediators - and try to give some examples of problems which arise to which there could be more than one ethical answer. I shall also consider the possibility of regulation - an evergreen topic of conversation between mediators. In addition, thanks to my American colleague Larissa Lieberman, I will incorporate some of the attempts to create a regulatory regime in the United States, where mediation has been practised for decades. The European Code of Conduct for Mediators expresses in simple terms the basic requirements which the European Commission considered were necessary for the proper conduct of mediations. They are similar to those set out in the United States in the Model Standards for Conduct of Mediators. In summary, they deal with: impartiality, no conflict of interest, competence, confidentiality, quality of the process, advertising and solicitation, transparency over fees and charges, advancement of the mediation practice and self-determination. Many of these areas overlap but, in the main, they are universally accepted as the basic ethical

Michel Kallipetis QC FCIArb is the former Head of Littleton Chambers, and has 40 years' experience as a practising barrister in the field of general commercial, professional negligence and employment work. requirements for any mediator. There is also the view that the type of mediation being conducted could influence the extent to which ethical principles may apply. The generally accepted classification is between facilitative, evaluative and transformative mediation. 'Facilitative' mediation which stresses the importance of the mediator's neutrality and party autonomy to help the parties develop their own problem solving capacity limits the ability of the mediator to 'steer' or guide the parties towards a settlement. 'Evaluative' mediation which helps the parties to assess the strength of their position and their opponents and the potential settlements based upon law and practice again creates a different problem for mediators as to how far they should 'push' or 'steer' the parties towards a particular settlement. Lastly, 'transformative' mediation which focuses on personal growth enabling the parties to develop a better recognition of their own goals, values and capacities and a greater empathy for the concerns of others brings with it its own different applications of ethical standards as far as the mediator is concerned. This contribution is far too short to consider all the ramifications in respect of each of these mediation styles, and therefore of necessity it will set out general principles and, in particular, consider the attempts made in the United States and Australia to regulate the process to see whether or not some form of regulation ought to be considered in the UK.

Regulation is always a burning issue. Some attempt at regulation of standards has been promulgated, notably by the International Mediation Institute but also by other countries in the European Union. The European Commission has toyed with Regulation for some time but, as yet, has been unable to draft Rules acceptable to all 27 Member States. The proselytisers of regulation argue that they want parties to have confidence in mediation, particularly in those countries where it is still a relatively new process, and perceive a need to hold mediators accountable in order to enable the consumers to have trust in the process. However, any attempt to standardize an ethical code for mediators creates its own difficulties and challenges. Any code has to take account of the interdisciplinary nature of the mediation and accommodate the flexibility of the process which most mediators would consider absolutely essential for any successful mediation. There is an understandable reluctance to overburden mediators and the mediation process with regulation, but perhaps the most important and most difficult question is deciding which body should regulate mediators and what sanctions ought that organization apply. The cost of an effective organization to regulate the conduct of mediators and adjudicate alle- 
gations of breaches of a Code is likely to prove prohibitive and raises an even more contentious issue as to how it should be funded. It is hardly likely that the mediators themselves would consider funding this, and certainly it is not something which any Government in the current economic climate would consider to be an essential part of public expenditure.

In Europe, various Member States have enacted codes of conduct applicable for mediators acting in their own jurisdiction. Most of these relate to Court-appointed mediations. The European Code of Conduct for Mediators was promulgated by the EU Commission before the EU Directive on ADR was implemented by the European Parliament. This Code of Conduct sets out a number of principles to which individual mediators can voluntarily decide to commit, under their own responsibility. It was intended to be applicable to all kinds of mediation in civil and commercial matters. For the purposes of the Code, mediation was defined as "any process where two or more parties agree to the appointment of a third party - hereinafter 'the mediator' - to help the parties to solve the dispute by reaching an agreement without adjudication and regardless of how that process may be called or commonly referred to in each Member State'. Adherence to the Code is specifically without prejudice to national legislation or rules regulating individual professions. The Code itself deals with the usual basic principles that one would expect, they are:

1. Independence and impartiality;

2. The fairness of the process and the procedure;

3. Fees;

4. Confidentiality;

5. Enforcement of any awards arrived at the conclusion of the mediation.

The Code itself is fairly basic, of necessity when one is dealing with 27 Member States, each with its own view about the effect or otherwise of mediation. Moreover, there is no compulsion about the Code and, as yet, no regulation to enforce it.

As already stated, the real and most practical difficulty with any ethical code is enforcement. Most responsible mediation providers have some form of code with which they expect their panel of mediators to comply, and if one of its mediators fails to do so, then the mediation provider itself may take action against the mediator. In addition, the Mediation Provider may be at risk of suit by the parties who have been disadvantaged as a result.

In the United States, there have been various attempts to set standards. It is instructive to consider what success such attempts have had. There is no clear regulation of mediator ethics. There is no State in the United States which licences mediators. No State has a binding ethical code for all mediators with a formal disciplinary board. However, regulation is increasing; at least 27 States have statutory or judiciary-appointed standards of conduct and formal disciplinary boards for Court-appointed mediators. Those rules often specify the qualifications necessary for such mediators. As with the UK, mediator organizations and private ADR providers have adopted their own standard. There are some specialized areas of mediation, for example, child custody, patients and those suffering with disabilities, where individual organizations have set their own standards for the mediators who mediate such disputes. All of the standards are either guidelines for mediators or model rules that act as guidance for States in creating standards. As such, none of them are actually enforceable unless a particular State has enacted them into law.

Moral Standards of Conduct for Mediators was first promulgated in 1994 and revised in 2005 by the American Bar Association section of Dispute Resolution, The American Arbitration Association and the Association for Conflict Resolution. These serve as guidelines. The areas covered, as one would expect, are self-determination, impartiality, conflicts of interest, competence, confidentiality, qualitative process, advertising and solicitation, fees and other charges and advancement of the mediation practice. The basic criticism levelled against the Moral Standard is that there is insufficient specific detail about the penalties if the outline values are at odds with each other.

The uniform Mediation Act approved by the National Conference of Commissioners on Uniform State Laws and approved by the American Bar Association provided guidelines for States in enacting laws pertaining to mediation. By 2011 ten States, plus the District of Columbia, have approved some version of the Uniform Mediation Act; this includes provisions regulating confidentiality and conflicts of interest.

The Model Rules for The Lawyer acting as a Third Party Neutral (2002) promulgated by the Georgetown Commission on Ethics and Standards of Practice in ADR provide model rules for states to adopt regarding ethical responsibility of lawyers serving as third party neutrals. These rules include rules on diligence and competence, confidentiality, impartiality, conflicts of interest, fees, fairness and integrity of the process.

Lastly, the ABA Model Rules of Professional Conduct, edited in 2005 to add two new rules expressly referring to mediators, provides for regulation as far as lawyers are concerned when mediating. In summary, it requires mediators to distinguish their role clearly from representing counsel. Rule 2.4 defines the distinction thus:

(a) a lawyer serves as a third party neutral when the lawyer assists two or more persons who are not clients of the lawyer to reach a solution of a dispute or other matter between them. Service as a third-party neutral may include service as an arbitrator, a mediator or in such other capacity as to enable the lawyer to assist the parties to resolve the matter.

(b) A lawyer serving as a third party neutral should inform unrepresented parties that the lawyer is not representing them. When the lawyer knows or reasonably should know that the party does not understand the lawyer's role in the matter, the lawyer should explain the difference between the 
lawyer's role as a third-party neutral and a lawyer's role as one who represents a client.

Rule 1.12 which applies to a former judge, arbitrator, mediator or other third party neutral provides guidance for mediators for resolving conflicts of interest that might arise from having previously served in a neutral capacity. The rule provides:

(a) Except as stated in paragraph (d), a lawyer shall not represent anyone in connection with the matter in which the lawyer participated personally and substantially as a judge or other adjudicative officer or law clerk to such person or as an arbitrator, mediator or other third party neutral, unless all parties to the proceeding give informed consent, confirmed in writing.

(b) A lawyer shall not negotiate for employment with any person who is involved as a party or as a lawyer for a party in a matter in which the lawyer is participating personally and substantially as a judge or other adjudicative officer or as an arbitrator, mediator or other third party neutral. A lawyer serving as a law clerk to a judge or other adjudicative officer may negotiate for employment with a party or lawyer involved in a matter in which the clerk is participating personally and substantially but only after the lawyer has notified the judge or other adjudicative officer.

(c) If a lawyer is disqualified by paragraph (a) no lawyer in any firm with which the lawyer is associated may knowingly undertake or continue representation in a matter unless:

(1) the disqualified lawyer is timely screened from any participation in the matter and is apportioned no part of the fee therefrom; and

(2) written notice is promptly given to the parties and any appropriate tribunal to enable them to ascertain compliance within the provision of the law.

(d) An arbitrator selected as a partisan of a party in multimember arbitration panel is not prohibited from subsequently representing that party.

Professor Menkel-Meadow's basic principles as set out in The Lamyer as a Consensus: Ethics for a Nem Practice (2002) provide a basic ethical framework for mediators, neutral consensus builders or facilitators. The rules are designed to ensure broad party and stakeholder participation and provide opportunities for participants to agree on procedural and ground rules, as well as on decision rules for agreements. They encourage participant recognition of both individual and joint leaders of interests and encourage parties to express reasons and justifications for their views, needs and offers. They facilitate creative and tailored solutions to meet the parties' needs and objectives and provide a place of fair hearing and respect for all parties. They also provide for the facilitation of capacity building and parties to negotiate on their own behalf.
Interestingly, they also provide for the consideration of the practicality and enforcement of agreements reached, provided of course that they must be free from bias and conflicts of interest and avoids unjust, unfair or unconscionable agreements wherever possible. The latter is an intriguing provision. When discussing the European Code of Conduct for Mediators, a long debate was held (driven mainly by the European Consumer Association representative) as to whether or not there should be included within the Code a provision that a mediator should not allow the parties to enter into what was described as an 'unconscionable bargain'. Experienced mediators will readily appreciate that the difficulty with such a proposition is that frequently mediators are unaware of the full extent of the parties' reasons for entering any particular settlement. Once the mediator is put into the position of assuming an obligation to judge whether or not an agreement is 'fair or unconscionable', any challenge to the agreement after the mediation inevitably will involve the mediator himself. In my opinion, this oversteps the universally accepted principle of an independent mediator whose task is to facilitate an agreement without actually imposing his own resolution.

The difficulty of course arises if a mediation settlement agreement is patently unworkable. In those circumstances, it is generally accepted, and certainly my view, that it is the mediator's obligation to point this out to the parties' representatives and ensure as far as is possible that the defect is remedied - a fortiori, if an agreement is patently unlawful, or breaches fiscal or other legislative provisions. In such circumstances, it would be quite wrong for a mediator to ignore the problem, and his obligation is to make the parties' representatives aware of the potential difficulty and assist if he can in resolving it. In short, pointing out potential difficulties in a settlement agreement is a prudent and necessary part of a mediator's obligations to ensure that the parties are entering into the settlement with full knowledge and informed consent. This is a far cry from assessing the fairness of the agreed terms: allowing an agreement to be signed by the parties in the knowledge that, sooner or later, it could be open to challenge not only does not serve the parties' interests but also inevitably will involve the mediator at some stage in the future in some form of suit, particularly if he is forced to acknowledge that he was aware of the difficulty and kept silent.

There are obviously ethical issues where a party is not represented by lawyers. The difficulty is assessing how much assistance a mediator can give without actually being considered to be advising the party. This is potentially one of the most difficult situations for a mediator. It is my practice to make arrangements with an unrepresented party for him to have access to a lawyer for advice by telephone, if necessary during the mediation but in any event on the proposed mediation settlement. Failing all else, it is prudent to suggest that the parties do not actually complete the agreement until the individual who is unrepresented has had the benefit of legal advice upon it. This is a far safer way to proceed and 
protects both parties and the mediator from any suggestion of coercion or lack of informed consent to any settlement.

It is generally accepted that the mediator should explain his role and the process, discuss obligations concerning confidentiality and the ground rules for any sessions in private with one or other of the parties. It is also beyond doubt that a mediator should disclose any potential grounds of bias or conflict of interest which may give rise to questions about the mediator's impartiality. Often overlooked is the mediator's obligation to advise the parties that they may suspend or terminate the mediation in circumstances where they either conclude there is no useful purpose being served by continuing with it or if one or other party has said or done something which causes them to doubt the bona fides of the other. The mediator should also have reserved to himself the right to terminate the mediation if he learns of matters which make it impossible for him to continue. It is not only good practice but essential that all mediators should ensure that parties sign a mediation agreement which clearly establishes the contractual basis of the mediation.

One of the difficulties with the purist view of selfdetermination by the parties is that the primary role of the mediator is to facilitate a voluntary resolution of the dispute. However, most experienced mediators will know that there are situations which arise when the parties do require and, indeed, some request assistance from the mediator to get them towards a settlement. In such a situation, can it be right for a mediator to refuse? How the help is given, and to what extent, inevitably will depend upon the circumstances, the nature of the dispute, the mediator's relationship with the parties and the ability of their respective lawyers to assist. Most will agree that it would be quite wrong and unethical for a mediator to advise a client in the absence of their lawyer. In some instances, particularly Court-appointed mediations, there is a pressure upon the parties and the mediator to achieve a settlement. Moreover, mediators on a personal level, whatever their protestations to the contrary may be, often like to be able to say that they have 'resolved a dispute'. Some parties may even chose mediators upon the basis of their settlement rate. This leads to another difficulty which I shall turn to later when dealing with ethical advertising.

The issue of self-determination raises the question: "how far should a mediator use persuasive tactics to push the parties towards a negotiated settlement?" Other than in general terms, this is an impossible question to answer. No party should ever feel under pressure from the mediator; on the other hand, mediators have been criticized for failing to 'test us' on our case. Reality testing is a feature which is taught, and indeed practised, by most mediators, but how far does this go? Like all ethical principles, it is a question of degree. If the mediator senses that there is resistance to a particular line, then of course he should stop. On the other hand, there may be situations where he is unaware that his attempt to push the parties towards a settlement is becoming oppressive. A competent lawyer will be quick to 'call off' an overzealous mediator and protect his client from any undue pressure. Inevitably, however, there are situations beyond the control of the mediator in which parties are bound to feel pressurized in mediation. A party with no legal defence may well feel there is a pressure upon them to achieve a deal to avoid the inevitability of a judgement. There is hardly a mediation during which one party will not assert an intention to litigate in the absence of settlement. Almost as a matter of course the mediator will be asked to take a message accompanying 'a last and final offer' that failure to accept will precipitate an open or without prejudice offer in the litigation in similar or lesser terms. Is this coercion? Most of us would say obviously not because it reflects the reality of the situation. However, one person's reality is another person's pressure.

The quintessential rule is that a mediator should promote honesty and candour between and among participants and never knowingly misrepresent any material fact or circumstance in the course of a mediation. This is also a principle which is easily stated but more difficult to apply in a particular circumstance. Persuading parties often involves 'manipulating' information available to the parties and the mediator. 'Reframing' offers and presenting facts in a positive light are standard techniques which every mediator uses. More difficult yet is the situation, which quite often occurs, where one party says "I want to tell you this but I don't want you to pass it on to the other side". One cannot erase the information from one's mind, and thus, in spite of every effort not to use it deliberately there is every possibility that one might inadvertently say or hint something which reveals the knowledge that has been given to you in confidence. Cynics might suggest that is precisely the reason why the information was given in the first place!

This gives rise to the next question as to what is adequate disclosure by the mediator to the parties. Most people would agree that a mediator should be totally open and frank. Usually the standards draw a distinction between an affirmative misrepresentation of material facts and passive non-disclosures. Some scholars would argue that it is unethical to condone passive nondisclosures by mediators; that again is a moot point. There are ways and means of indicating that one is in possession of knowledge that one cannot share. If the other side suspects that this is the position, then, in my view, the best solution is for the mediator to tell the other party that for various reasons he believes that the other is aware of the fact of this information and, in the best interests of getting to a settlement, they ought to share it. Again, each circumstance is different and the mediator must just simply use his best judgement guided by the principles that he must no knowingly mislead.

Even evaluating a circumstance for parties is not without difficulty. Overzealous mediators often exaggerate the risks of non-settlement and overemphasize the benefits of settlement. If the parties are unrepresented, this 
is an area fraught with peril for the incautious mediator. It is good practice, as well as a prudent precaution, for any such messages to be given to both parties in plenary rather than in private and to be done in a non-directive fashion: Do you know how much a trial will cost? Have you any idea of the difficulties involved in preparing for trial? Do you know what remedies are available to the court? Answers given by a mediator in such an environment, especially if couched in terms "I suggest that you seek advice as to...etc." are less likely to give rise to a complaint of oppressive or coercive behaviour by the mediator. If the parties are represented by competent lawyers, they will be in a position to resist any of this overzealous interference by a mediator.

One of the issues raised by the principle of self-determination, frequently encountered by mediators, is the overzealous lawyer who is effectively 'calling the shots'. It is difficult to judge how far mediators should intervene between a client and his lawyer. It is even more difficult if one suspects that the lawyers' judgement is in fact unsound and even more difficult if he has simply got the law wrong. In the latter case, it is my practice to take the lawyer aside and have a quiet chat with him about the law, if necessary referring him to a particular authority or statute which gives me cause to doubt the accuracy of the advice being given. If the lawyer refuses to accept it, there is not much one can do. I doubt whether anyone would consider that it would be ethical for a mediator to advise the client to seek advice from another lawyer. If a discussion with the lawyer in the presence of his client about the relevant legal principles fails to put the client on guard, then there is little else a mediator can properly do. In extreme circumstances, I have held a 'tutorial' with both sets of lawyers discussing the law in the presence of their respective clients, so that they can as far as possible make an informed judgement as to the risks of litigation. One of the ethics problems often posed in seminars is the dilemma facing a mediator who learns of a recent court decision which completely undermines one side's legal argument, of which both parties' lawyers are ignorant. Should the mediator keep the information to himself: generally the universal answer is 'no'. Should he inform one party and not the other: surprisingly this has never produced a uniform answer! Should the mediator in the opening plenary session reveal the decision without warning to the party who is disadvantaged by the case? Usually most mediators consider that would be unfair. The better approach is to inform the lawyers of the party who will be disadvantaged by the case and ask whether they are aware of it. If not, it gives them an opportunity to rethink his client's position and advise his client on an appropriate stance to adopt.

\section{Impartiality}

The requirement of impartiality is generally interpreted as exercising neutrality towards all the participants and to have no bias in relation to the subject matter. There is often a debate on how detached a mediator should be. There are two different views on mediation neutrality. Some commentators argue that neutrality means that mediators should prevent their own values from biasing the outcome. Others argue that neutrality requires a structuring of process that will ensure meaningful participation, informed decision making and a reasonable balance of power between the parties to promote fairness in the process. Whichever formulation is preferred, there are complications for creating ethical standards since most mediators tailor their approach to different mediations depending upon the nature of the dispute, the nature of the parties and perceived need for any mediator 'intervention' at any particular time. Obviously a mediator will avoid actual and perceived bias and will ensure that there is a procedurally fair process. Most mediators will refuse to act if they perceive they are unable to be impartial, and most will withdraw if a situation arises where their impartiality is no longer beyond doubt. It is essential that mediators disclose any information that might lead to questions about their impartiality but provided they make a full disclosure and the parties give informed consent then there could be no criticism at all. One of the most difficult issues is the question of should parties refuse a mediator simply because that mediator has acted as mediator in a dispute with one of the other parties' representatives previously. There may be different considerations if he has acted in a dispute involving one of the parties themselves, but as far as the representatives are concerned, bearing in mind that most mediators will agree that their mediation practice depends upon referral, it would be inconceivable that having mediation once for a particular firm of lawyers, the mediator should never again be able to act in a mediation where that firm who is representing one of the parties. Nonetheless, some purists argue this is something that ought to be disclosed. In these days of Legal Directories which list and grade mediators on the basis of research garnered from those who have used them, inevitably people will be relying upon personal experience or comments from others when selecting a mediator. Thus it is not a question of impartiality but more a question of experience. Most researches carried out in the legal community confirm that experience is one of the essential criteria when selecting a particular mediator.

One of the other areas where there is considerable debate is the question of accepting gifts or items of 'kindness' from any party involved. This is a question that pertains not only to mediators but to practitioners in general. After a successful representation of a client, would it be wrong for a lawyer to accept a bottle of wine or a bunch of flowers as 'thank you' from a grateful client. Most would say obviously no, but where do you draw the line? If the client is extremely well off and proffers a case of very expensive and rare claret, does that overstep the mark? So it is with mediators. Is a mediator obliged to declare an expensive gift from a lawyer for whose client he has conducted a mediation, if 
that lawyer is representing another party in a later mediation? The guiding rule should be whether or not accepting such gifts impairs the mediator's independence, and therefore his ability to act impartially. This is not a subjective test but an objective test: does such a situation create the appearance of bias?

The Model Standard II provides that the mediator must conduct the mediation in an impartial manner and actually directs the mediator to withdraw from a mediation or terminate a mediation if the ability to act impartially is compromised and that could include situations, according to the Model Standard, where there is a party imbalance. Rule 4.5.3 of the Model Rules for Third Party Neutrals seems to strike a balance between the different views of neutrality. In essence, it boils down to this. Most mediators will accept that, as human beings, their feelings are bound to influence their view about the merits of a particular case. The importance of course is not to allow that to influence the way that they conduct their mediation. Expressing empathy with a claimant who has suffered terrible injuries is hardly compromising one's impartiality. Persuading insurers to make a sensible offer in such circumstances is hardly to justify a suggestion that the mediator is being partial. Most users would regard that as a mediators inculcating realism. Experienced litigators know that most judges will have empathy and sympathy with claimants who have suffered terrible injuries or damage, particularly if there is a dubious defence law, and a mediator who challenges a party on a position which is tenuous is doing what the parties have appointed him to do. Arguments as to causation and quantum of damages are everyday stuff for lawyers in Court and, if raised in mediation, the fact that the mediator will engage vigorously in such a debate with one or other of the parties does not in any way affect his impartiality. When one considers all these factors, I believe the equation is better expressed as 'the mediator is impartial as to the result but not neutral as to the facts'.

\section{Conflicts of Interest}

The objective aspect of neutrality is that the parties must believe, based upon any disclosures the mediator makes, that mediator is neutral in the sense that he does not have any conflict of interest. Primarily most guidelines are concerned with the neutrality of the mediator towards participants and their advocates. Many enquiries focus upon mediators that were previously partners within a representative firm in the mediation or mediators providing other services to parties after the mediation. Most mediators who are still partners in a firm of solicitors or members of barristers' chambers will have difficulty in persuading parties that there is no conflict of interest if they conduct a mediation in which one of their partners or fellow member of chambers may be representing one of the parties.
All the standards, including the European Code of Conduct, require the mediator to disclose any actual or potential conflict of interest. The UMA and Model Standards require reasonable investigation and disclosure of potential and actual conflicts. It is common practice for those representing clients to send details to the organization or to the mediator of the parties and ask for a declaration that there is no conflict of interest. If the parties chose to engage the mediator after a full disclosure, then clearly they waive any objection based upon the disclosed information, and any attempt then to set the mediation aside on this ground is unlikely to succeed.

Model Standards III require mediators to disclose promptly any potential or actual conflicts of interest and seek the consent of the parties to continue in the face of any possible conflict. The rules also require the mediator to withdraw, even if a party consents, if the conflict of interest "might reasonably be viewed as undermining the integrity of the mediation". Model Standard III goes further than the Uniform Mediation Code because it has restrictions on what a mediator can do after the mediation. It cannot establish a relationship with any of the parties. This does not preclude a mediation from serving in another mediation with a party involved in the previous mediation but does prevent him acting for that party in any subsequent litigation. This sensible distinction is probably uncontentious in most jurisdictions.

The universally accepted practice requires the mediator to make full disclosure of any actual or potential conflict and seek the parties' consent. Prudent practitioners will do this in writing. It is sensible that the mediator, when making a disclosure, has in mind the guidance, enshrined in both the Model Standard and in the UMA, namely, "might the conflict of interest be reasonably viewed as undermining the integrity of the mediation". Some commentators have argued that this approach undermines the parties' autonomy and freedom to choose a mediator if the mediator refuses to act on this basis, even though the parties themselves may consent to his continuing. However, under the UMA, if a mediator fails to disclose a potential conflict, the mediator is precluded from asserting privilege as to mediation communications made by the mediator.

An often asked question is should the mediator withdraw from a mediation if they know one of the parties socially or professionally? The answer is straightforward: provided full disclosure of the nature of the relationship is given to the parties, it is a matter entirely for them. The greatest risk is that the mediated settlement agreement could be set aside for a mediator's failure to disclose an interest. In such a case, it is highly likely that the mediator would be personally liable for breach of contract. 


\section{Competence}

All mediators must comply with whatever standards are required for any particular organization. Some mediators are asked in particular whether they are familiar with a particular area of law or subject matter. Should this be a matter for a Code of Conduct or regulation? Common sense dictates that it would be a foolish mediator who misrepresents his experience or competence to act in any particular dispute, not least because as far as the marketplace is concerned, that would be the end of his reputation as a mediator. That is sufficient safeguard for most practical purposes.

There is not such a clear line about a mediator having 'subject matter expertise'. Arguments against suggest that a mediator is less likely to be biased if they have less knowledge about the subject. On the other hand, those proponents who argue for a mediator with subject matter expertise consider the mediation is more likely to be successful because the mediator will more readily understand the complexities of the subject matter. The purist will say that a good mediator can mediate any dispute regardless of what the subject matter is. As a purist view, this may be correct but in reality if parties want the mediator to have mediation experience of a particular subject matter, then they should be entitled to have it and the mediator would be foolish to try to insist that he or she is able to conduct such a mediation if they do not possess the detailed knowledge that the parties consider he should require. Again this is more a matter of practicality than ethics.

\section{Confidentiality}

This subject alone is worthy of a book! I shall deal with it in general terms in this contribution given the limitations. There are several sources of confidentiality in mediation. In principle, the provisions are to be found in the mediation agreement which is signed by the parties as a precursor to the mediation itself. In the United States, there are various federal and State rules for evidence, some based upon the Uniform Mediation Act, others upon local statutes which provide for the confidentiality of the dispute resolution process. In general terms, confidentiality must be maintained at all times unless both parties agree otherwise, or to the extent permitted by law. It is this latter qualification which has given rise to much difficulty in the UK. Courts in England and Wales have taken the view that the 'interests of justice' can justify judicial enquiry into what transpired in mediation (see Farm Assist and AB v CD). Courts in California, on the other hand, have set their face against any revelations as to what happened in mediation and there is an absolute bar upon evidence being adduced of what happened in mediation. There are various degrees in between these two extreme views. In general, most parties would expect that the process is confidential and that unless both parties agree to some aspect of that confidentiality being waived, they would expect that to be maintained. It is essential that the mediator explains the confidentiality provisions at the beginning of the mediation and reminds the parties throughout the mediation, if required, that these are the conditions under which everybody is operating. Whether a mediator, particularly in England and Wales, should go on to explain the complexities of the Court's decision in Farm Assist is a moot point. Personally I think not: it adds an unnecessary complication, and in any event there is far too much uncertainty as to what the Courts might do.

There are two aspects of a mediator's confidentiality obligations in the context of ethical standards which need to be addressed: the external and the internal confidentiality. The internal confidentiality is the mediator's obligation during the course of the mediation not to disclose to any party any confidential information provided by the other. Most mediators will make it a rule that whatever is disclosed to them in caucus remains private and confidential unless specifically authorized by that party for disclosure to the other side. It goes without saying that a mediator is, of course, under a general obligation not to disclose anything revealed to him in mediation by either party to any person outside. This is the external confidentiality and the requirement is not only upon the mediators but on the parties and all those present at the mediation in order to maintain the confidentiality of the mediation, even after the mediation session itself has been concluded. It is also axiomatic that any documents, or other communications prepared specifically for the mediation, are covered by the same confidentiality. I would prefer to use the word privilege as this is much more meaningful as far as lawyers are concerned.

As far as the internal confidentiality is concerned, most mediators, and all in the UK, operate on the basis that information received from one party is confidential unless that party expressly authorizes it to be disclosed to the other side. Some mediators, notably those in the United States, shift the burden to the parties by informing them that they will disclose all information they are given unless specifically requested not to. It is a question of culture and experience, but most mediators would agree that it is far safer to operate on the first principle and, if the message is at all controversial, prudence suggests reducing it to an agreed written form before it is taken to the other side.

The ethical dilemma for the mediator arises when he is in possession of knowledge from one party which, if imparted to the other party, may assist them to a settlement. He cannot, of course, 'leak' the information itself (which would be a clear breach) but how far, if at all, may he impart by subtle means any important strategic information to the other side? Disabusing one party's misconceptions of the other, particularly where that is creating an impediment to settlement, is an essential role for the mediator. The question is how? Judge Richard Posner commented that a mediator, to help 
parties come to a common estimate of the outcome of a judgement on the dispute, must "not only be a conduit of information between opposing sides but also an impediment to transparent communication between them". If removing that impediment requires disclosure of confidential information, the mediator must find a way. Most mediators, faced with such a dilemma, would explain to the party concerned the need to disclose the information to the other in the interests of correcting a misconception and moving both parties towards achieving a settlement.

There is no ethical difficulty where one party is seeking to use confidentiality as a cloak for fraud or for some criminal activity. It is universally accepted that where the interests of children, patients and minors are involved, where the approval of a court is required for any settlement, confidentiality is no bar to informing the court of all relevant matters which may have occurred in mediation.

As far as external confidentiality, i.e. communications after the mediation session itself, is concerned, there is a vast range of possibilities. In the United States, there are several enactments which govern the position. Paragraph 2 of the Uniform Mediation Act provides a definition of mediation communications. The limitations imposed by the Federal Rule of Evidence 408 and the tier privilege structure used in the UMA paragraph 4 , provide guidelines as to what can or cannot be disclosed after the mediation. The Model Standard V requires a mediator to maintain the reasonable expectation of the parties with regard to confidentiality. Section 8 of the Uniform Mediation Act and the Federal Rules of Evidence provide that offers to compromise, including settlement offers, and evidence of conduct or statements made in compromised discussions, including any admission of legal responsibility, are inadmissible in evidence in any Federal Court. It is not impossible for parties prior to the mediation to agree between themselves a confidentiality agreement which limits the extent to which information they are sharing may be used afterwards. But no private contract can create an enforceable privilege not to testify if a Court decides that the evidence of a party or mediator is required at trial in the interest of justice. It is axiomatic that agreements between parties are not enforceable against non-signatories.

In the United States, nearly every State has some sort of legislation providing for some protection of mediation. Usually Court-sponsored mediations are not protected to the same extent as private mediations. Protection for the state of the mediation, the type of information that can be imparted and who could invert the privilege. There is no uniform approach and no uniform agreement between the Federal States in the United States as to the approach to be adopted. Similarly in England and Wales, the general view is that the mediation is totally confidential, but there are decisions where the Courts have taken a different view in somewhat special circumstances. It is unfortunate that these decisions have yet to be reviewed with informed argument by an appellate
Court. Some argue that it would be far better to enact a mediation statute establishing mediation privilege and provide for the same limited circumstances where the courts will exceptions as privilege is in common law that are well known to all practitioners.

\section{European Implementation of Mediation Ethics}

Pursuant to the EU ADR Directive, most Member States have implemented the Directive itself in ways consistent with their respective legal system. However, not all have provided a Code of Conduct for Mediators directed at the various ethical issues raised in this paper, and those that have, have not applied a common approach to some of the core standards which should be standard, particularly if the cross-border provisions of the Directive are to be effective. Most make provision that the mediator must have a minimum qualification. Austria's Civil Law Mediation Act enacts that the Federal Minister of Justice maintains a list of Registered Mediators. To qualify for registration, mediators must be at least 28 years old, professionally qualified and possess professional indemnity insurance. Belgium's Law on Mediation requires registered mediators to have a minimum training and are required to take part in continuing education. Failure to comply with its Code of Conduct may result in loss of accreditation. However, the Belgian Code of Conduct also provides that the accredited mediator "must possess, by present or past activity, the qualifications required by the nature of the dispute". In Bulgaria, the Minister for Justice determines accreditation of mediators and they are then entered on the Uniform Register of Mediators. As far as ethical conduct is concerned, Article 9(1) of the 2004 Mediation Act requires the mediator to act in good faith, in compliance with the law, good morals and the ethical rules of mediation'. The Croatian Chamber of Commerce has promulgated Mediation Rules which give the mediator a wide latitude under Article 6(3) to conduct the mediation "in the manner he deems appropriate, taking into consideration the circumstances of the case, the expressed wishes of the parties, and the interest for the dispute between the parties to be concluded quickly and permanently". The Czech Republic has similar provisions in its Mediation Act, while France requires the mediator in court-annexed mediations to act in accordance with the Civil Code of Procedure.

Germany requires mediators to be certified according to the provisions of Para 5(1) of the Mediation Law, which requires mediators to ensure that they have the training, knowledge and experience to guide the parties through mediation with an additional requirement for continuing education. Greece's Mediation Law provides for a Mediation Certification Board operating under the Ministry of Justice to certify mediators. It has decreed that a domestic mediator must be a qualified lawyer 
(Article 7) but not a Notary Public. Presidential Decree 123 of 2011 sets out the conditions and requirements for approval of mediation training centres, and Ministerial Decision 109088 sets out the requirement for continuing education as a condition of continued registration. The Mediation Act of Hungary has enacted that the List of Registered Mediators be maintained by the Ministry of Administration and Justice. Section 3 of the Act requires a mediator to "mediate to the best of his ability and in an unbiased and conscientious manner".

Ireland has no harmonized law, but an excellent draft Mediation Bill produced after the superb Report of the Law Reform Commission is waiting for Parliamentary time to be enacted. The Mediator's Institute of Ireland has its own Code of Ethics and Practice to which individual members subscribe and is a model template illustrating the difficulties as well as the solution to the various issues raised in this paper. I can do no better than quote from the section entitled Scope of Code:

4. We have attempted to cover as many aspects of mediation and the process as possible in this Code. However, it must be understood that every mediation is unique and its very success depends on its retaining its flexibility. Every Mediator will mediate differently to every other Mediator and will mediate each of their cases differently depending on the type of mediation, the subject matter of the mediation and the interaction of all of the people in the Mediation Session and on their own training and experience.

5. It is not possible to cover every scenario and, further, there may be occasions when the particular situation requires a different approach. Although, generally, a mediation will go through some or all of the steps below, some mediations may not allow for that approach or may not allow for the steps to be gone through in that order. It is the Mediator's decision as to how the mediation should proceed taking all of the circumstances into account.

6. There is no "right" process or "right" way to mediate and, in the event of an issue arising in relation to a particular mediation, the totality of the mediation will have to be taken into account in assessing whether there was a breach of this Code of Ethics and Practice.

The challenge then for the mediation community in Europe is to agree upon a common Code of Ethical Conduct to which all professional mediators in Europe subscribe and thus present a uniform mediation standard of behaviour so that, regardless of the specific jurisdiction in which the mediation takes place, all parties will know that the same standard of excellence will be adhered to by any European mediator. This Code should not be drafted by the EU Commission, or indeed by any specific Member State's Justice Department, but ought be drawn up by practising mediators, who, from actual experience rather than theory, know the pitfalls, the temptations and the solutions. The Irish mediators have shown the way, and the rest of European mediators should now take up the baton and produce a uniform Code of Ethics for European mediators. If we can succeed in this endeavour, we will have achieved something which even those jurisdictions which have been mediating for decades have yet to achieve. A piecemeal approach will not solve the problem, and the best thing that the EU Commission can do is to arrange a conference of practising professional mediators to start the task. The benefits will be enormous, and perhaps the cross-border limitations of the ADR Directive will no longer be a bar to the adoption of mediation as a first choice for resolving all disputes in every Member State. 